\title{
Epilepsy-Associated KCNQ2 Channels Regulate Multiple Intrinsic Properties of Layer 2/3 Pyramidal Neurons
}

\author{
Zachary Niday, $\odot$ Virginia E. Hawkins, Heun Soh, ๑Daniel K. Mulkey, and $\oplus^{\circledR A n a s t a s i o s ~ V . ~ T z i n g o u n i s ~}$ \\ Department of Physiology and Neurobiology, University of Connecticut, Storrs, Connecticut 06269
}

KCNQ2 potassium channels are critical for normal brain function, as both loss-of-function and gain-of-function KCNQ2 variants can lead to various forms of neonatal epilepsy. Despite recent progress, the full spectrum of consequences as a result of KCNQ2 dysfunction in neocortical pyramidal neurons is still unknown. Here, we report that conditional ablation of Kcnq2 from mouse neocortex leads to hyperexcitability of layer 2/3 (L2/3) pyramidal neurons, exhibiting an increased input resistance and action potential frequency, as well as a reduced medium afterhyperpolarization (mAHP), a conductance partly mediated by KCNQ2 channels. Importantly, we show that introducing the KCNQ2 loss-of-function variant $\mathrm{KCNQ} 2{ }^{\mathrm{I} 205 \mathrm{~V}}$ into $\mathrm{L} 2 / 3$ pyramidal neurons using in utero electroporation also results in a hyperexcitable phenotype similar to the conditional knock-out. KCNQ2 ${ }^{\mathrm{I} 205 \mathrm{~V}}$ has a right-shifted conductance-to-voltage relationship, suggesting loss of KCNQ2 channel activity at subthreshold membrane potentials is sufficient to drive large changes in L2/3 pyramidal neuronal excitability even in the presence of an intact mAHP. We also found that the changes in excitability following Kcnq2 ablation are accompanied by alterations at action potential properties, including action potential amplitude in Kcnq2-null neurons. Importantly, partial inhibition of $\mathrm{Na}_{\mathrm{v}} 1.6$ channels was sufficient to counteract the hyperexcitability of Kcnq2-null neurons. Therefore, our work shows that loss of KCNQ2 channels alters the intrinsic neuronal excitability and action potential properties of L2/3 pyramidal neurons, and identifies $\mathrm{Na}_{\mathrm{v}} 1.6$ as a new potential molecular target to reduce excitability in patients with KCNQ2 encephalopathy.

Key words: epilepsy; KCNQ2; KCNQ3; potassium channels; sodium channels

Significance Statement

KCNQ2 channels are critical for the development of normal brain function, as KCNQ2 variants could lead to epileptic encephalopathy. However, the role of KCNQ2 channels in regulating the properties of neocortical neurons is largely unexplored. Here, we find that Kcnq2 ablation or loss-of-function at subthreshold membrane potentials leads to increased neuronal excitability of neocortical layer 2/3 (L2/3) pyramidal neurons. We also demonstrate that Kcnq2 ablation unexpectedly leads to a larger action potential amplitude. Importantly, we propose the $\mathrm{Na}_{\mathrm{v}} 1.6$ channel as a new molecular target for patients with KCNQ2 encephalopathy, as partial inhibition of these channels counteracts the increased L2/3 pyramidal neuron hyperexcitability of Kcnq2-null neurons.

\section{Introduction}

Two decades ago, genetic studies implicated KCNQ2 and KCNQ3 potassium channel dysfunction as a likely cause for benign familial neonatal seizures (BFNSs), an epileptic neonatal

Received April 29, 2016; revised Nov. 9, 2016; accepted Nov. 24, 2016.

Author contributions: Z.N., V.E.H., D.K.M., and A.V.T. designed research;Z.N. and V.E.H. performed research; H.S. contributed unpublished reagents/analytic tools; Z.N. and A.V.T. analyzed data; Z.N., V.E.H., and A.V.T. wrote the paper.

This work was supported by National Institutes of Health Grants F32-HL-126381 (to V.E.H.), HL-104101 (to D.K.M.), and NS-073981 (A.V.T.). Additional support comes from Connecticut Department of Public Health Grant 150263 (to D.K.M. and A.V.T.). We thank the members of the Tzingounis laboratory for discussions and reading of the manuscript.

The authors declare no competing financial interests.

Correspondence should be addressed to Dr. Anastasios V. Tzingounis, Department of Physiology and Neurobiology, University of Connecticut, Storrs, CT 06299. E-mail: anastasios.tzingounis@uconn.edu.

DOI:10.1523/JNEUROSCI.1425-16.2016

Copyright $\odot 2017$ the authors $\quad 0270-6474 / 17 / 370576-11 \$ 15.00 / 0$ disorder characterized by seizures that spontaneously remit within the first year of life (Charlier et al., 1998; Singh et al., 1998). More recently, targeted and whole exome sequencing revealed that KCNQ2 and KCNQ3 variants are also linked to severe forms of neonatal epileptic encephalopathy, including Ohtahara syndrome and, potentially, infantile spasms (Saitsu et al., 2012; Weckhuysen et al., 2012; Allen and Monyer, 2013; Kato et al., 2013). The main features of these forms of encephalopathy are progressive cognitive deterioration and an early onset of severe seizures that do not respond to most antiepileptic drugs (Auvin et al., 2016). Thus, there is a pressing need for new therapeutic agents.

Currently, the majority of KCNQ2 encephalopathy variants are loss-of-function and dominant negative (Orhan et al., 2014); that is, the presence of only one copy of the variant is sufficient to alter the properties of the tetrameric potassium channel complex. 
These pathogenic variants most commonly result in reduced voltage sensitivity or current density due to changes in surface expression or the maximum probability of opening (Orhan et al., 2014). Despite this knowledge, it is still unclear how the loss of KCNQ2 leads to hyperexcitability in neocortical neurons, thus causing epileptogenesis. Furthermore, most studies using Kcnq2 transgenic mice have focused on CA1 pyramidal neurons (Peters et al., 2005; Otto et al., 2006; Singh et al., 2008; Soh et al., 2014), and there are no validated KCNQ2-specific inhibitors available. Understanding the full spectrum of KCNQ2 channel function in the neocortex is critical to uncovering how these channels contribute to disease etiology and to the development of improved therapeutic approaches.

KCNQ2 channels are enriched in the axon initial segment (AIS) — the site of spike initiation (Pan et al., 2006; Battefeld et al., 2014). Importantly, recent work has shown that the AIS is plastic, such that neuronal activity typically leads to changes in its length or localization with respect to the soma (Grubb and Burrone, 2010). In particular, chronic elevated neuronal activity could lead the AIS to move closer to the soma or shorten its length, whereas decreased activity may lead to the opposite effect (Kole and Stuart, 2012). These changes can subsequently tune neuronal excitability, and have been implicated in demyelination and Angelman syndrome (Kaphzan et al., 2011; Hamada and Kole, 2015). Therefore, the electrophysiological effects of disrupting KCNQ2 in neurons might also result from alterations in the AIS.

In this study, we show that KCNQ2 ablation from neocortical neurons leads to increased neuronal activity of layer 2/3 (L2/3) somatosensory pyramidal neurons. Furthermore, the introduction of a KCNQ2 pathogenic variant $\left(\mathrm{KCNQ} 2{ }^{\mathrm{I} 205 \mathrm{~V}}\right)$ with a rightshifted conductance-to-voltage relationship in L2/3 pyramidal neurons using in utero electroporation (IUE) resulted in a hyperexcitable phenotype similar to Kcnq2 ablation, despite the normal expression of a medium afterhyperpolarization (mAHP). Additionally, our results also show that L2/3 pyramidal neurons from Kcnq2 knock-out (KO) mice have increased action potential (AP) amplitude without observing any corresponding changes to the AIS length measured either through Ank-G or Pan-Nav staining. Importantly, selective pharmacological blockade of $\mathrm{Na}_{\mathrm{v}} 1.6$ in Kcnq2-null neurons successfully counteracted the elevated KCNQ2-induced hyperexcitability. Therefore, we propose $\mathrm{Na}_{\mathrm{v}} 1.6$ channels as a new molecular target for patients with KCNQ2 encephalopathy.

\section{Materials and Methods}

All experiments were performed according to the guidelines of the University of Connecticut (Storrs, CT) Institutional Animal Care and Use Committee.

Animals and genotyping. Kcnq2 conditional $\mathrm{KO}(\mathrm{cKO})$ mice have been described before. See Soh et al., 2014 for details on the Kcnq2 transgenic mouse line and genotyping protocols. For $\mathrm{Na}_{\mathrm{v}} 1.6$ genetic ablation, we obtained and used the C3Fe.Cg-Scn $8 a^{\text {med }} / \mathrm{J}$ mouse line from The Jackson Laboratory. Mice were genotyped by PCR as described on the Jax.org website. In brief, the following three primers were included in the PCR: a wild-type forward primer ( $5^{\prime}$-TCA GGA GCA AGG TTC TAG GC-3'), a mutant forward primer ( $5^{\prime}$-TAC CAA AAG TCC CCA TAC CC- $\left.3^{\prime}\right)$, and a common reverse primer ( $5^{\prime}$-AGG AGT GGC GCT AAA TCT GA-3'). The primers amplified a $164 \mathrm{bp}$ wild-type fragment and/or an $82 \mathrm{bp}$ mutant fragment.

Slice preparation and electrophysiology. Postnatal day 15 (P15) to P20 mice were anesthetized using isoflurane (Baxter Healthcare) and killed by decapitation. Brains were quickly removed and placed in ice-cold cutting solution consisting of the following: $26 \mathrm{~mm} \mathrm{NaHCO}_{3}, 210 \mathrm{~mm}$ sucrose, $10 \mathrm{~mm}$ glucose, $2.5 \mathrm{~mm} \mathrm{KCl}, 1.25 \mathrm{~mm} \mathrm{NaH}_{2} \mathrm{PO}_{4}, 0.5 \mathrm{~mm} \mathrm{CaCl}_{2}$, and $7 \mathrm{~mm} \mathrm{MgCl}{ }_{2}$. Cerebella were removed, and $300 \mu \mathrm{m}$ coronal slices were cut using a vibratome (Microm HM 650 V, ThermoFisher Scientific). Slices were then transferred to a holding chamber containing artificial CSF (aCSF) consisting of the following: $125 \mathrm{~mm} \mathrm{NaCl}, 26 \mathrm{~mm}$ $\mathrm{NaHCO}_{3}, 2.5 \mathrm{~mm} \mathrm{KCl}, 1 \mathrm{~mm} \mathrm{NaH} \mathrm{PO}_{4}, 1.3 \mathrm{~mm} \mathrm{MgCl}_{2}, 2.5 \mathrm{~mm} \mathrm{CaCl}_{2}$, and $12 \mathrm{~mm}$ D-glucose. Slices were recovered at $35^{\circ} \mathrm{C}$ for $30 \mathrm{~min}$ then were left at room temperature (RT; $\sim 22^{\circ} \mathrm{C}$ ) for $\geq 1 \mathrm{~h}$ before electrophysiological recording. Both cutting and aCSF solutions were saturated with $95 \%$ $\mathrm{O}_{2} / 5 \% \mathrm{CO}_{2}$.

Whole-cell recordings were obtained using electrodes pulled from thin-walled borosilicate glass capillaries (World Precision Instruments, Sarasota, FL) that had resistances of 2-4 M $\Omega$ when filled with recording solution, as described below. Pyramidal neurons from L2/3 somatosensory cortex were visually identified using infrared differential interference contrast optics (Olympus BX51WI, Olympus). The internal recording solution for whole-cell recording consisted of the following: $125 \mathrm{~mm}$ potassium gluconate, $20 \mathrm{~mm} \mathrm{KCl,} 4 \mathrm{~mm} \mathrm{Mg} \cdot \mathrm{ATP}, 0.3 \mathrm{~mm}$ $\mathrm{Na} \cdot G T P, 10 \mathrm{~mm}$ HEPES, $0.1 \mathrm{~mm}$ EGTA, and $10 \mathrm{~mm}$ phosphocreatine (osmolarity, $\sim 278 \mathrm{mOsm}$ ). The $\mathrm{pH}$ was adjusted to $7.2-7.3$ with $\mathrm{KOH}$. The previously described aCSF was used as the external bathing solution, and contained $100 \mu \mathrm{M}$ picrotoxin, $4 \mu \mathrm{M}$ 6-cyano-7-nitroquinoxaline-2,3-dione (CNQX), and $25 \mu \mathrm{M}$ D-2-amino-5-phosphonovaleric acid (D-APV) to block GABA-mediated, AMPA-mediated, and NMDA-mediated synaptic transmission, respectively. All reported potential values were corrected for the liquid junction potential, calculated to be $-14.4 \mathrm{mV}$. Resting membrane potential was determined in current clamp as the potential upon break-in, before any current injection. AP threshold was defined as the membrane potential at which the rate of depolarization reached $100 \mathrm{mV} / \mathrm{ms}$. All recordings were performed at RT using a Multiclamp 700B Amplifier (Molecular Devices), low-pass-filtered at $2 \mathrm{kHz}$, and sampled at $10 \mathrm{kHz}$. Data were analyzed off-line using Axograph X (Axograph), Clampfit (Molecular Devices), Prism 7 software (GraphPad), or MATLAB (MathWorks).

In utero electroporation. Surgery was performed on pregnant female mice of age approximately embryonic day 15 (E15; CD-1 background from Charles River Laboratories). Mice were anesthetized first with isoflurane, then with a mixture of ketamine/xylazine $(100 / 10 \mathrm{mg} / \mathrm{kg}$, i.p.). Full anesthetization was confirmed by the lack of response to a toe pinch. Metacam analgesic $(2 \mathrm{mg} / \mathrm{kg}$, s.c.) was administered for $2 \mathrm{~d}$ following surgery. Surgery comprised a vertical incision along the abdominal midline and removal of the uterine horns. Embryos were kept moist with a $0.9 \%$ saline solution containing $1 \%$ penicillin/streptomycin. One lateral ventricle of each embryo was pressure injected with the DNA mixture via a pulled glass pipette (Drummond Scientific). Pressure was supplied by pulses delivered from a Picospritzer III (Parker). The $15 \mu \mathrm{l}$ DNA mixtures contained the following: $\sim 1.5 \mu \mathrm{g} / \mu \mathrm{l}$ pCMV-hKCNQ2 WT or pCMV-hKCNQ2 ${ }^{\mathrm{I} 205 \mathrm{~V}}, \sim 1.0 \mu \mathrm{g} / \mu \mathrm{l}$ pCAG-mRFP, and $1 \mu \mathrm{l}$ of $5 \%$ Fast Green in sterile PBS, to visualize the mixture entering the embryonic ventricle. Following mixture injection, each embryo was electroporated by delivering four $40 \mathrm{~V}^{2}$ pulses of $50 \mathrm{~ms}$ duration using a BTX 830 Pulse Generator (BTX Harvard Apparatus) coupled with BTX Tweezertrode Electrodes.

HEK293T cell preparation and electrophysiology. Recombinant DNA was expressed in HEK293T cells using Lipofectamine 2000 (Invitrogen) transfection. Cells were transfected with either wild-type hKCNQ2 or hKCNQ2 ${ }^{\text {I205V }}$ subcloned into a pIRES2-DsRed-Express vector (Clontech), and recordings were obtained $48 \mathrm{~h}$ later to allow for sufficient plasmid expression. Experiments were performed using conventional whole-cell patch-clamp electrophysiology in voltage-clamp configuration, and recordings took place at room temperature. Pipette electrodes were pulled to have resistances of $2-4 \mathrm{M} \Omega$ and were filled with an intracellular solution containing the following: $132 \mathrm{~mm}$ potassium gluconate, $10 \mathrm{~mm} \mathrm{KCl,} 4 \mathrm{~mm} \mathrm{Mg}$ •ATP, 20 mm HEPES, and 1 mm EGTA (osmolarity $\sim 290 \mathrm{mOsm}$ ). The $\mathrm{pH}$ was adjusted to $7.2-7.3$ with $\mathrm{KOH}$. Cells were superfused in an extracellular solution containing the following: $144 \mathrm{~mm}$ $\mathrm{NaCl}, 2.5 \mathrm{~mm} \mathrm{KCl}, 2.25 \mathrm{~mm} \mathrm{CaCl}_{2}, 1.2 \mathrm{~mm} \mathrm{MgCl}, 10 \mathrm{~mm}$ HEPES, and 22 mM D-glucose (osmolarity, $\sim 300 \mathrm{mOsm}$ ). The $\mathrm{pH}$ was adjusted to $7.2-$ 7.3 with $\mathrm{NaOH}$. The voltage-clamp holding potential and steps were corrected to account for a $-14.4 \mathrm{mV}$ liquid junction potential, resulting 
in a holding potential of $-70 \mathrm{mV}$ with $1.5 \mathrm{~s}$ steps ranging from -80 to $+40 \mathrm{mV}$, changing in increments of $10 \mathrm{mV}$. Tail currents were measured at $-55 \mathrm{mV}$ following the step depolarization to determine the conductance-to-voltage relationships of KCNQ2 and KCNQ2 ${ }^{\mathrm{I} 205 \mathrm{~V}}$. Data were acquired through a MultiClamp 700B Amplifier (Molecular Devices), low-pass Bessel filtered at $2 \mathrm{kHz}$, and sampled at $10 \mathrm{kHz}$. Whole-cell capacitance was compensated for during each recording. Data were analyzed using both Clampfit (Molecular Devices) and IgorPro (WaveMetrics), and statistical analyses were performed with Prism 7 software (GraphPad).

Immunohistochemistry. Mice (P15) were anesthetized and perfused with ice-cold saline followed by $1 \%$ paraformaldehyde in $\mathrm{pH} 7.4$ PBS. Brains were removed, and tissue was postfixed overnight at $4^{\circ} \mathrm{C}$. Excess fixative was removed by three washes in PBS, and $60 \mu \mathrm{m}$ tissue sections were prepared using a vibrating blade microtome (VT1000 S Vibratome, Leica Biosystems). Before antibody incubations, tissue sections were treated to unmask epitopes with $0.2 \mathrm{mg} / \mathrm{ml}$ pepsin (Sigma-Aldrich) in $0.2 \mathrm{M} \mathrm{HCl}$ at $37^{\circ} \mathrm{C}$ (Corteen et al., 2011) followed by three washes in PBS. A blocking stage was then performed by incubating tissue in $10 \%$ normal horse serum in PBS with 10\% Triton X-100 (Sigma-Aldrich) for $1 \mathrm{~h}$ at RT. Sections were then incubated overnight at RT with primary antibodies diluted in blocking solution as follows: 1:50 rabbit anti-ankyrin G (AnkG; Santa Cruz Biotechnology; RRID: AB_633909), and 1:800 mouse anti-PanNaV (Sigma-Aldrich; RRID: AB_477552). After washes in $\mathrm{PBS}$, tissues were incubated for $1 \mathrm{~h}$ at RT with the appropriate secondary antibodies raised in donkey, conjugated with 1:800 ${ }^{488}$ DyLight or 1:500 Cy3 (both from Jackson ImmunoResearch Laboratories; RRID: AB_2492289 and AB_2315777, respectively). Sections were washed in PBS again before being mounted with Vectashield containing DAPI (Vector Laboratories). Images were acquired using a Nikon A1R confocal microscope (Nikon Instruments), maintaining identical settings between each series of experiments and with minimal background staining observed in the control reactions where primary antibodies were omitted. For confocal photomicrographs, two-dimensional flattened images of the projected $z$-stacks are presented. Image analysis was performed using ImageJ measurement options. Briefly, freehand linear regions of interest (ROIs) were selected for six to eight AISs per image on a single $z$-plane, and mean intensity values for each channel were calculated. Similarly, AIS ROIs were selected, and length was measured in projected stacks (each with identical intervals and number of $z$-sections) in pixels and subsequently converted to micrometers. All analyses were performed in a blinded manner.

Drugs. Recordings from mouse brain slices included the following synaptic blockers in the extracellular solution: picrotoxin (100 $\mu \mathrm{M}$; Abcam), CNQX (4 $\mu \mathrm{M} ;$ Abcam), and D-APV (Abcam). Selective block of $\mathrm{Na}_{\mathrm{v}} 1.6$ was achieved with the tetrodotoxin (TTX) analog 4,9-anhydroTTX (ahTTX; 100 nм; Focus Biomolecules).

Statistical analysis. Data are displayed as the mean \pm SEM, and significance was determined with a Student's $t$ test, a Mann-Whitney $t$ test, or a two-factor mixed-design ANOVA using Prism software (GraphPad). The $n$ values indicate the number of cells.

\section{Results}

KCNQ2 channels regulate $\mathrm{L} 2 / 3$ pyramidal neuron excitability Although KCNQ2 channels are expressed in pyramidal neurons of upper cortical layers, their contribution in setting neuronal excitability is not yet clear. To examine this directly, we used Kcnq2-cKO mice, as specific KCNQ2 pharmacological blockers are not available. To ablate KCNQ2 channels from pyramidal neurons, we crossed $\mathrm{Kcnq} 2^{f / f}$ mice to the Emx1 ${ }^{\mathrm{Cre}}$ line; Emx1 ${ }^{\mathrm{Cre}}$ mice express Cre recombinase in neocortical pyramidal cells at an early developmental stage (E10.5; Gorski et al., 2002). Previously, we found that the majority of $E m \times 1^{C r e}: K c n q 2^{f / f}$ mice die by the third week of life (Soh et al., 2014). Thus, we tested the effects of ablating KCNQ2 channels in P15-P20 pyramidal neurons. Consistent with previous studies in CA1 pyramidal neurons (Soh et al., 2014), ablation of KCNQ2 channels reduced the mAHP of

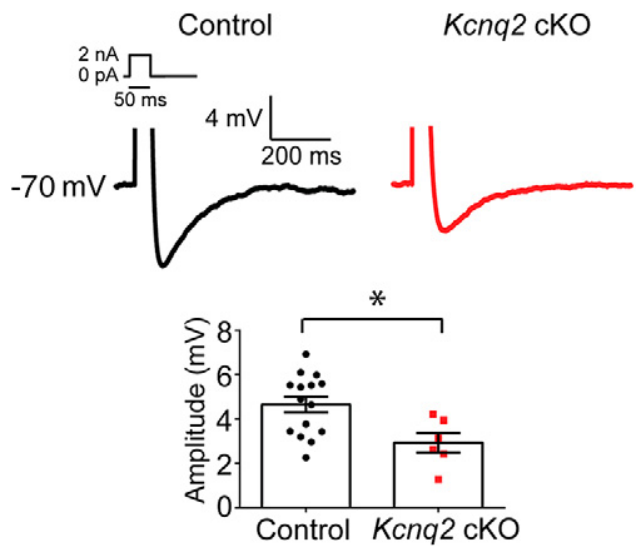

Figure 1. Kcnq2 ablation reduces the $L 2 / 3$ pyramidal neuron medium afterhyperpolarization. Top, Representative examples of the mAHP following a brief suprathreshold stimulus (50 $\mathrm{ms}, 2 \mathrm{nA}$ ) in L2/3 pyramidal neurons from either control or Kcnq2-null neurons. Bottom, Summary graph showing that the peak mAHP amplitude in Kcnq2-null $\mathrm{L} 2 / 3$ pyramidal neurons is reduced compared with control cells (control: $-4.64 \pm 0.35 \mathrm{mV}, n=15 ; \mathrm{Kcnq} 2$ cK0: $-2.94 \pm 0.44 \mathrm{mV}, n=6 ; p<0.05$, Mann-Whitney test). Bar graphs plot the mean $\pm \mathrm{SEM}$ values. Asterisks indicate statistically significant differences $\left({ }^{*} p<0.05\right)$.

somatosensory L2/3 pyramidal neurons (control, $-4.64 \pm 0.35$ $\mathrm{mV}, n=15 ; \mathrm{Kcnq} 2 \mathrm{cKO},-2.94 \pm 0.44 \mathrm{mV}, n=6 ; p<0.05$, Mann-Whitney test; Fig. 1). The mAHP is a conductance that limits repetitive firing (Bean, 2007).

We next examined whether Kcnq2 ablation altered the intrinsic membrane properties of L2/3 pyramidal neurons. To induce firing, we depolarized pyramidal neurons by injecting currents of variable amplitude for $1 \mathrm{~s}$. As shown in Figure 2, increasing the magnitude of the injected current from +25 to $+250 \mathrm{pA}$ in increments of +25 pA led L2/3 pyramidal neurons to fire APs in greater number and frequency (Fig. $2 A$ ). We found that Kcnq2null neurons were hyperexcitable ( $+150 \mathrm{pA}$ step; control, $8.1 \pm$ 0.6 APs, $n=21$; Kcnq 2 cKO, $11.3 \pm 0.5$ APs, $n=18$; $p<0.001$, Student's $t$ test; Fig. $2 A$ ) and fired APs with greater initial firing frequency - the frequency measured between the first two APsthan control neurons $(+150 \mathrm{pA}$ step; control, $13.8 \pm 1.6 \mathrm{~Hz}, n=$ 21; Kcnq2 cKO, $21.3 \pm 2.0 \mathrm{~Hz}, n=18 ; p<0.01$, Student's $t$ test; Fig. 2A). Similarly, the final firing frequency, measured as the frequency of the last two APs during the depolarizing steps, increased across a range of depolarizing stimuli in Kcnq2-null neurons ( $+150 \mathrm{pA}$ step; control, $6.7 \pm 0.5 \mathrm{~Hz}, n=21 ; \mathrm{Kcnq} 2 \mathrm{cKO}$, $9.6 \pm 0.6 \mathrm{~Hz}, n=18 ; p<0.001$, Student's $t$ test; Fig. $2 A)$. The input resistance, measured at resting membrane potential followed by a small hyperpolarizing step ( $-25 \mathrm{pA}$ ), of Kcnq2-null neurons was also larger than in control pyramidal neurons (control, $239 \pm 17 \mathrm{M} \Omega, n=21$; Kcnq $2 \mathrm{cKO}, 299 \pm 18 \mathrm{M} \Omega, n=18$; $p<0.05$, Student's $t$ test), which is consistent with earlier studies that used pharmacological approaches to block all KCNQ channels in pyramidal neurons (Guan et al., 2011).

The activation and deactivation kinetics of KCNQ2 channels are slow, leading them to limit action potential firing in response to slow depolarizing stimuli. To examine the influence of KCNQ2 channels on the activity of gradually induced L2/3 pyramidal neurons, we measured excitability by using a slow ramp protocol (+100 pA/s; Fig. 2B). Similar to the step protocol, the ramp protocol induced a greater number of APs in Kcnq2-null neurons (control, $9.2 \pm 1.3$ APs, $n=10$; Kcnq 2 cKO, $13.8 \pm 1$ APs, $n=12 ; p<0.05$, Student's $t$ test; Fig. $2 B$ ). Together, these findings further confirm that KCNQ2 activity is critical in regulating repetitive neuronal activity in $\mathrm{L} 2 / 3$ pyramidal neurons. 
A

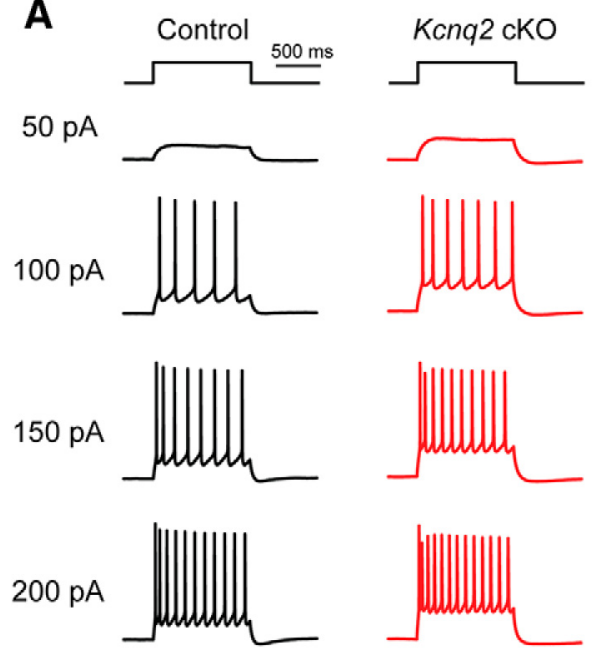

B

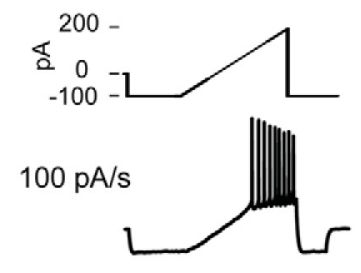

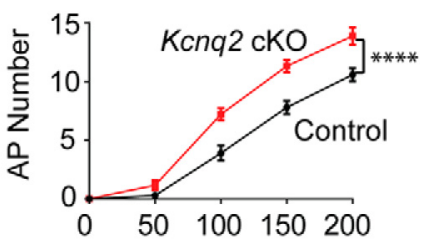
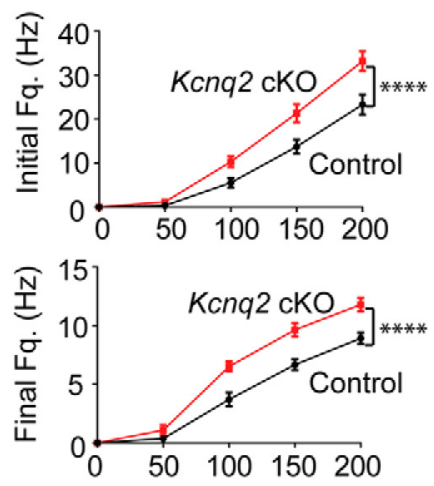

Current injection(pA)

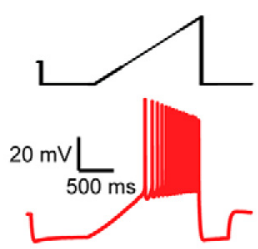

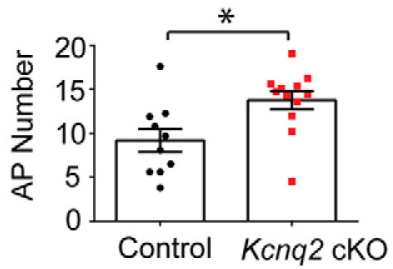

Figure 2. Kcnq2 ablation leads to increase neuronal excitability of $\mathrm{L} 2 / 3$ pyramidal neurons. $\boldsymbol{A}$, Left, Representative voltage responses to various current injection steps ( $1 \mathrm{~s}$ from +50 to $+200 \mathrm{pA}$ ) in L2/3 pyramidal neurons from control or Kcnq2-null neurons. Membrane potential was kept at $-84 \mathrm{mV}$ by injecting a small direct current (DC) through the recording pipette. Right, Summary graphs showing the effect of deleting KCNQ2 channels on AP number and the initial and final frequency (AP number: $F_{(4,148)}=9.37, p<0.0001$; initial frequency: $F_{(4,148)}=8.17, p<0.0001$; final frequency: $F_{(4,148)}=9.24 ; p<0.0001$, two-factor mixed-design ANOVA). $\boldsymbol{B}$, Left, Representative voltage responses to a current injection ramp ( $2.5 \mathrm{~s}$ ramp from $-100 \mathrm{pA}$ to +200 $\mathrm{pA} ; 0.1 \mathrm{nA} / \mathrm{s}$ ) recorded from control or Kcnq2-null L2/3 pyramidal neurons. Right, summary graphs showing the effect of ablating KCNQ2 channels on the number of APs during the ramp protocol (control: $9.2 \pm 1 \mathrm{APs}, n=10 ; \mathrm{Kcnq} 2 \mathrm{CK0}: 13.8 \pm 1 \mathrm{APs}, n=12$; $p<0.05$, Student's $t$ test). Using this protocol, we found that the rheobase for action potential generation was lower in Kenq2-null neurons (control: $196 \pm 9 \mathrm{pA}, n=10 ; K c n q 2 \mathrm{cK0}: 168 \pm 8 \mathrm{APs}, n=12 ; p<0.05, t=2.43$, Student's $t$ test). We did not find any significant differences in the resting membrane potential between control and $K c n q 2$-null neurons (control: $-67.3 \pm 0.8 \mathrm{mV}$ $n=49 ; K c n q 2$ cKO: $-65.7 \pm 1.1 \mathrm{mV}, n=39 ; p=0.2$, Student's $t$ test). Asterisks indicate statistically significant differences $\left({ }^{*} p<0.05,{ }^{* * * *} p<0.0001\right)$.

\section{The KCNQ2 pathogenic variant KCNQ2 ${ }^{\mathrm{I} 205 \mathrm{~V}}$ leads to increased $\mathrm{L} 2 / 3$ pyramidal neuron excitability}

KCNQ2/3 channels control neuronal excitability by the following two interrelated mechanisms: (1) regulating input resistance and axonal membrane potential by mediating the M-current; and (2) mediating an mAHP following a burst of activity. However, it is unknown whether the loss of KCNQ2-mediated mAHP, $\mathrm{M}$-current, or both is required to induce large changes in L2/3 pyramidal neuron excitability. This is particularly important as an increased number of KCNQ2 pathogenic variants shift the KCNQ2 voltage dependence toward more depolarized potentials (Millichap et al., 2016). Such shifts are expected to prevent the opening of KCNQ2 channels at subthreshold membrane potentials without necessarily altering their ability to gate the mAHP.

To address this, we expressed the KCNQ2 ${ }^{\mathrm{I} 205 \mathrm{~V}}$ pathogenic variant, first identified in a patient with epileptic encephalopathy (Weckhuysen et al., 2012), into L2/3 pyramidal neurons using IUE. $\mathrm{KCNQ} 2{ }^{\mathrm{I} 205 \mathrm{~V}}$ offered the following three key advantages (Orhan et al., 2014). First, no evidence suggests that it affects membrane trafficking. Second, it acts as a dominant negative; therefore, the incorporation of one variant channel into a KCNQ2/3 heteromeric complex is sufficient to alter the properties of the channel. Third, the right-shifted conductance-to-voltage relationship is not expected to reduce the mAHP, as the KCNQ2 ${ }^{\text {I205V }}$ variant could still maximally activate, albeit at more depolarized potentials $\left(V_{1 / 2} ; \mathrm{KCNQ} 2,-25.2 \pm 1.9 \mathrm{mV}, n=7\right.$; $\mathrm{KCNQ}^{1205 \mathrm{~V}},-10.6 \pm 3.1 \mathrm{mV}, n=7 ; p<$ 0.01 , Mann-Whitney test; Fig. 3A). Therefore, any changes in KCNQ2 ${ }^{1205 \mathrm{~V}}$-expressing neuron excitability are expected to be due to reduced KCNQ2/3 activity at subthreshold membrane potentials.

Consequently, we introduced $\mathrm{KCNQ} 2^{\mathrm{I} 205 \mathrm{~V}}$ into somatosensory $\mathrm{L} 2 / 3$ pyramidal neurons using IUE. This approach enabled us to modify only a subset of pyramidal neurons at an early developmental stage, therefore nullifying the complications of global excitability changes (Chen et al., 2014b). Furthermore, we transfected mice from a wildtype background to avoid potential compensatory mechanisms resulting from conditional Kcnq2 deletion; as a dominant negative, the KCNQ2 ${ }^{\mathrm{I} 205 \mathrm{~V}}$ variant is able to alter channel properties without relying on molecular replacement. We transfected the progenitors that line the lateral ventricle at E15 with our KCNQ2 constructs, because these cells eventually become the pyramidal neurons that migrate to $\mathrm{L} 2 / 3$ cortical layers. We identified transfected neurons through cotransfection of a monomeric red fluorescent protein. Previous work has shown that the efficiency of cotransfecting two plasmids with IUE exceeds $90 \%$ (Chen et al., 2014a; Siddiqi et al., 2014).

We recorded from P15-P20 L2/3 pyramidal neurons using the same approach that we used for Kcnq2 cKO mice. Similar to the Kcnq2-null neurons, we found that the overexpression of $\mathrm{KCNQ}^{2205 \mathrm{~V}}$ increased L2/3 pyramidal neuron excitability (Fig. $3 B, C)$. In particular, KCNQ2 $2^{1205 \mathrm{~V}}$-expressing neurons produced a greater number of APs (+150 pA step; KCNQ2, 7.1 $\pm 1.5 \mathrm{APs}$, $n=10 ; \mathrm{KCNQ}^{\mathrm{I}}{ }^{205 \mathrm{~V}}, 11.8 \pm 1.2 \mathrm{APs}, n=8 ; p<0.05$, MannWhitney test) and faster initial and final frequencies for any given stimulus ( +150 pA step, initial: KCNQ2, $14.3 \pm 3.4 \mathrm{~Hz}, n=10$; $\mathrm{KCNQ}^{2}{ }^{\mathrm{I205V}}, 42.8 \pm 11.8 \mathrm{~Hz}, n=8 ; p<0.01$, Mann-Whitney test; +150 pA step, steady-state: KCNQ2, $5.1 \pm 1.2 \mathrm{~Hz}, n=10$; $\mathrm{KCNQ}^{\mathrm{I} 205 \mathrm{~V}} 8.7 \pm 1.0 \mathrm{~Hz}, n=8 ; p<0.05$, Mann-Whitney test) compared with neurons overexpressing wild-type KCNQ2 channels. Additionally, we found that the input resistance increased in neurons expressing the KCNQ2 ${ }^{\mathrm{I} 205 \mathrm{~V}}$ variant $(\mathrm{KCNQ} 2,245 \pm 27$ $\mathrm{M} \Omega, n=10 ; \mathrm{KCNQ} 2^{\mathrm{I} 205 \mathrm{~V}}, 337 \pm 32 \mathrm{M} \Omega, n=8 ; p<0.05$, Mann-Whitney test). Importantly, both the mAHP amplitude and the charge between KCNQ2 and KCNQ2 ${ }^{1205 \mathrm{~V}}$ neurons were similar (Fig. 3D; mAHP: KCNQ2, $-5.5 \pm 1.4 \mathrm{mV}, n=7$; $\mathrm{KCNQ}^{1205 \mathrm{~V}},-5.0 \pm 0.8 \mathrm{mV}, n=4 ; p=0.77$; charge: $\mathrm{KCNQ} 2$, $-15.1 \pm 0.2 \mathrm{mV}^{\star} \mathrm{s}, n=7 ; \mathrm{KCNQ}^{\mathrm{I}}{ }^{\mathrm{I} 205 \mathrm{~V}},-14.7 \pm 0.4 \mathrm{mV}^{\star} \mathrm{s}, n=$ $4 ; p=0.527$, Mann-Whitney test), suggesting (1) that the observed neuronal excitability effects were not due to loss of the 


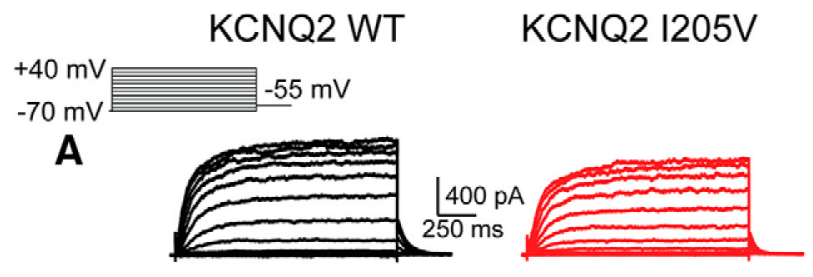

B

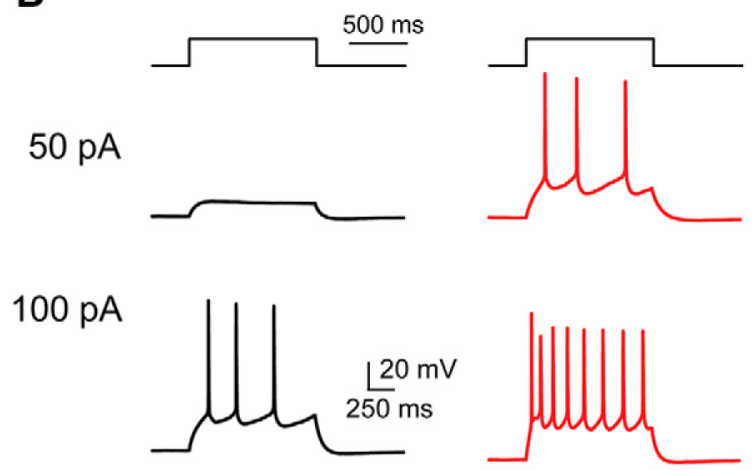

$150 \mathrm{pA}$

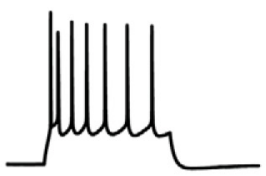

C

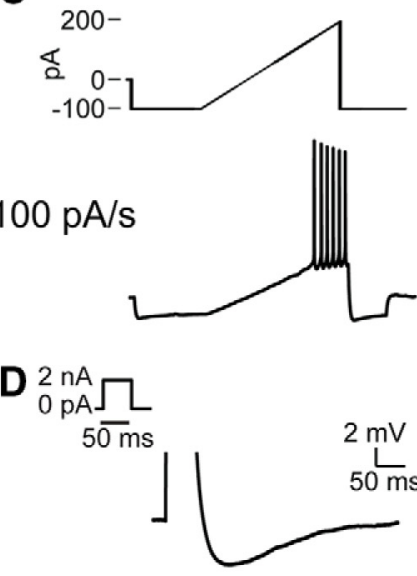

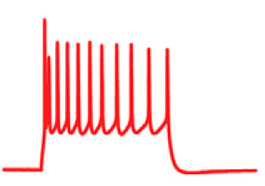
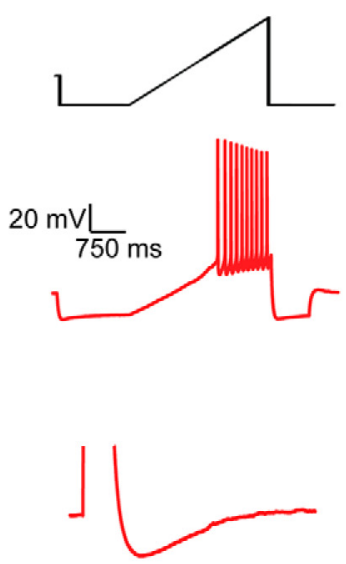
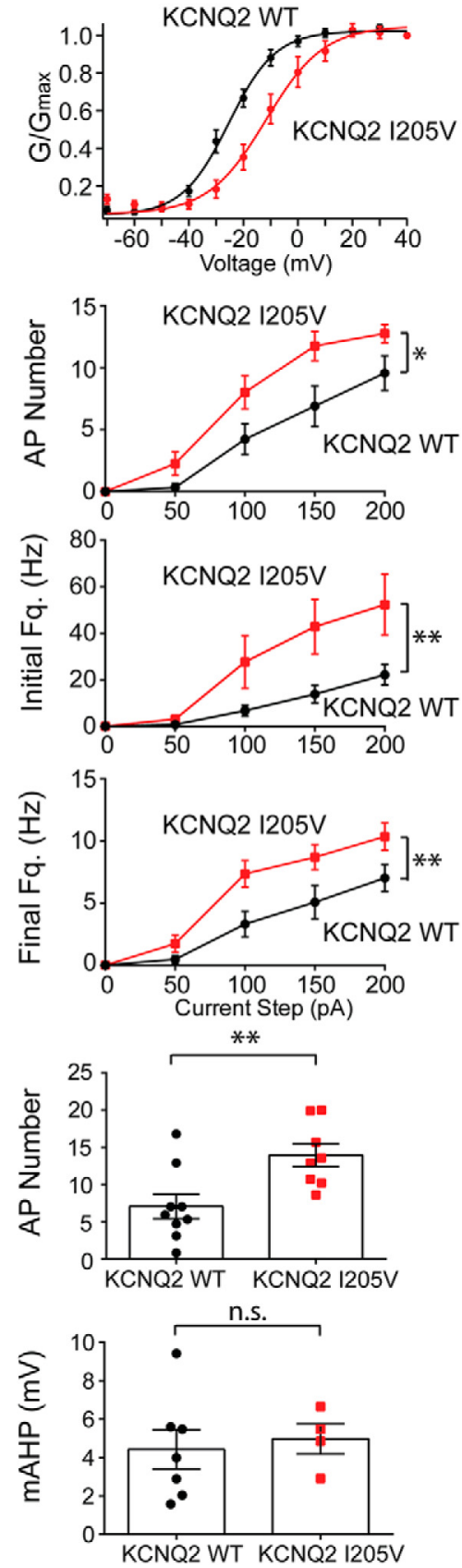

Figure 3. Loss-0f-function KCNQ2 variant KCNQ2 ${ }^{1205 V}$ leads to L2/3 pyramidal neuron hyperexcitability. $A$, Left, Representative current responses to incremental voltage steps (1 s from -70 to $+40 \mathrm{mV}$ ) in HEK293t cells transfected with either wild-type KCNQ2 or KCNQ2 ${ }^{1205 \mathrm{~V}}$. Right, Summary graph of conductance normalized to maximum conductance. Consistent with previous studies, KCNQ2 ${ }^{1205 V}$ caused a right-shifted $V_{1 / 2}$ in the conductance-to-voltage relationship (KCNQ2 WT: $-25.2 \pm 1.9 \mathrm{mV}, n=7 ; \mathrm{KCNQ2}^{1205 \mathrm{~V}}:-10.6 \pm 3.1 \mathrm{mV}, n=7 ; p<$ 0.01 , Mann-Whitney test) but did not affect the slope (KCNQ2 WT: $8.1 \pm 0.5, n=7 ; K_{C N Q 2}{ }^{1205 V}: 8.3 \pm 0.7, n=7 ; p=0.840$, Mann-Whitney test). $\boldsymbol{B}$, Left, Representative voltage responses to various current injection steps ( $1 \mathrm{~s}$ from +50 to $+200 \mathrm{pA}$ ) in L2/3 pyramidal neurons from cells expressing either KCNQ2 or KCNQ2 ${ }^{1205 \mathrm{~V}}$. Membrane potential was kept at $-84 \mathrm{mV}$ by injecting a small $D C$ current through the recording pipette. Right, Summary graphs showing the effect of expressing KCNQ2 ${ }^{1205 V}$ compared with cells expressing KCNQ2 in AP number and initial and final frequency (AP number: $F_{(4,64)}=3.01, p<0.05$; initial frequency: $F_{(4,64)}=5.00, p<0.01$; final frequency: $F_{(4,64)}=3.95, p<0.01$, two-factor mixed-design ANOVA). C, Left, Representative voltage responses to a current injection ramp (2.5 s ramp from -100 to $+200 \mathrm{pA} ; 0.1 \mathrm{nA} / \mathrm{s})$ recorded from KCNQ2 or KCNQ2 ${ }^{1205 \mathrm{~V}}$ transfected neurons and L2/3 pyramidal neurons. Right, Summary graphs showing the effect of ablating KCNQ2 channels on the number of APs during the ramp protocol (KCNQ2: $7.6 \pm$ $1.6, n=10 ; K_{C N Q 2}{ }^{1205 V}: 14.0 \pm 2, n=8 ; p<0.05$, Mann-Whitney test). Using this protocol, we found that the rheobase for action potential generation was not significantly different between KCNQ2 and KCNQ2 ${ }^{1205 V}$-transfected neurons (KCNQ2: $202 \pm 14 \mathrm{pA}, n=10 ; \mathrm{KCNQ2}^{1205 \mathrm{~V}}: 166 \pm 10 \mathrm{pA}, n=8 ; p=0.1$, Mann-Whitney test). $\boldsymbol{D}$, Left, Representative voltage responses to a strong but brief current step $(2 \mathrm{nA}, 50 \mathrm{~ms})$ to induce spiking. Right, Summary graph showing a lack of difference in mAHP amplitude between neurons overexpressing KCNQ2 wild-type or KCNQ ${ }^{1205 V}$-variant channels (KCNQ2: $-5.5 \pm 1.4 \mathrm{mV}, n=7 ; \mathrm{KCNQ2}^{1205 \mathrm{~V}}:-5.0 \pm 0.8 \mathrm{mV}, n=4 ; p=0.77$, Mann-Whitney test). Asterisks indicate statistically significant differences $\left({ }^{*} p<0.05,{ }^{* *} p<0.01\right)$. 
A

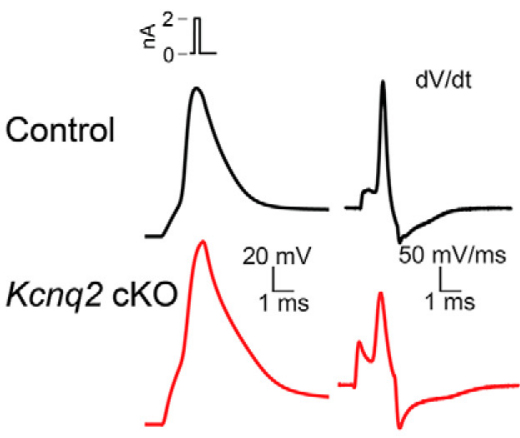

B
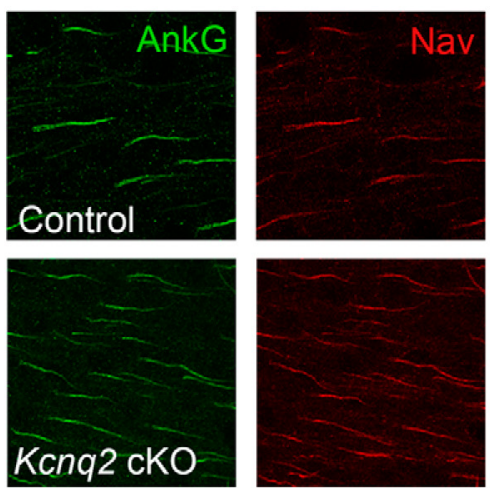

C

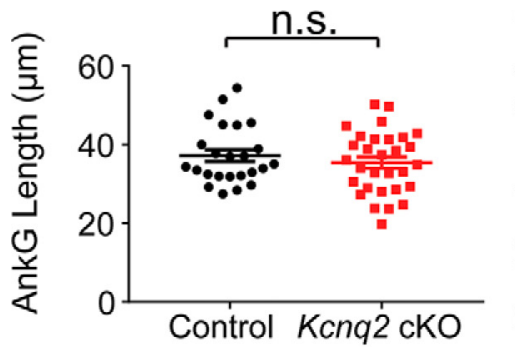

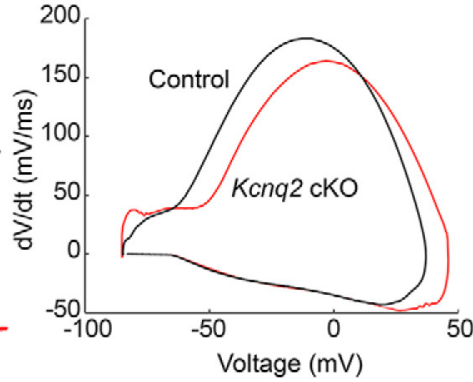
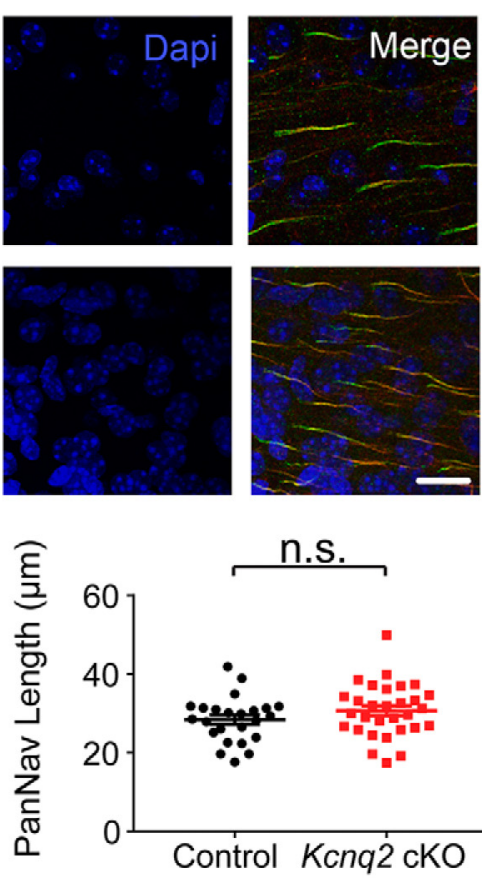

Figure 4. Kcnq2 ablation leads to changes in action potential properties. $\boldsymbol{A}$, Left and middle, Representative AP and dV/dt values from control and Kcnq2-null L2/3 pyramidal neurons. Right, AP phase plot from control $(n=22)$ and Kcnq2-null $(n=16) \mathrm{L} 2 / 3$ pyramidal neurons. AP threshold, defined as the voltage at $100 \mathrm{mV} / \mathrm{ms}$, is more depolarized in $K c n q 2$-null neurons (control: $-52.4 \pm 1.6 \mathrm{mV}, n=22 ; K c n q 2 \mathrm{cKO}:-36.7 \pm 5.0 \mathrm{mV}, n=16 ; p<0.01, t=3.23$, Student's $t$ test), and the maximum dV/dt is reduced (control: $226 \pm 6, n=22 ; K c n q 2$ cK0: $180 \pm 8, n=16 ; p<0.0001, t=4.62$, Student's $t$ test) compared with controls. $\boldsymbol{B}$, Representative confocal images of somatosensory cortex $\mathrm{L} 2 / 3$ neurons labeled for AnkG, PanNa , and DAPI to stain cell nuclei in control mice (top) and Kcnq2 conditional knock-out mice (bottom). Scale bar, $20 \mu \mathrm{m}$. C, Summary graphs showing the effect of Kcnq2 ablation on AnkG and PanNa vength. Neither the length of AnkG (control: $37.2 \pm 1.5 \mu \mathrm{m} ; n=24$; AIS, four animals; Kcnq2 cK0: $34.8 \pm 1.2 \mu \mathrm{m} ; n=38$; AlS, three animals; $p=0.218, t=1.25$, Student's $t$ test) nor the length of PanNa ${ }_{v}$ changed significantly (control: $28.4 \pm 1.2 \mu \mathrm{m} ; n=24$; AIS, four animals; Kcnq2 cK0: $30.2 \pm 1.0 \mu \mathrm{m} ; n=38$; AIS, three animals; $p=$ $0.272, t=1.11$, Student's $t$ test)

mAHP and (2) that KCNQ2 ${ }^{\mathrm{I} 205 \mathrm{~V}}$ was expressed in the transfected neurons. Had the KCNQ2 ${ }^{\mathrm{I} 205 \mathrm{~V}}$ variant failed to traffic or caused a global KCNQ2 trafficking defect in L2/3 pyramidal neurons, we should have also seen a loss to the MAHP as we did with the Kcnq2 cKO mice. We also note that, in contrast to transfected neurons, neighboring untransfected pyramidal neurons from the two experimental groups did not show any changes in their firing properties, suggesting that the differences between KCNQ2 and KCNQ2 ${ }^{\mathrm{I} 205 \mathrm{~V}}$ transfected slices were likely cell autonomous $(+150 \mathrm{pA}$ step; for KCNQ2 transfected slices: $8.5 \pm 1.2 \mathrm{APs}, n=4$; for KCNQ2 ${ }^{\mathrm{I} 205 \mathrm{~V}}$ transfected slices: $9.3 \pm 1.1$ APs, $n=8 ; p=0.8$, Mann-Whitney test)

\section{KCNQ2 ablation leads to action potential changes}

KCNQ channels in cortical neurons are enriched in the AIS, where they regulate sodium channel inactivation in part by setting the axonal resting membrane potential (Battefeld et al., 2014). Recent

work has shown that hyperexcitability can be accompanied by AIS changes, manifesting as alterations in length, location, or ion channel composition (Grubb and Burrone, 2010; Kaphzan et al., 2011; Hamada and Kole, 2015). As the loss of KCNQ2 channels leads to chronic hyperexcitability, we investigated whether action potential properties and AIS length changed in Kcnq2-null neurons.

First, we measured AP properties following a brief but large stimulation protocol (2 nA, 2 ms; Fig. 4A). Ablation of Kcnq2 led to a larger AP amplitude (control: $121 \pm 2 \mathrm{mV}, n=22 ; \mathrm{Kcnq} 2 \mathrm{cKO}$ : $131 \pm 4 \mathrm{mV}, n=16 ; p<0.05$, Student's $t$ test). To better quantify differences in AP properties between control and Kcnq2null neurons, we next took the first derivative $(\mathrm{dV} / \mathrm{dt})$ of the somatic recorded AP. As with previous studies from multiple groups, we found that the $\mathrm{dV} / \mathrm{dt}$ exhibited the following two inflections: the first inflection reflects the invasion of the AIS AP at the soma; whereas the second inflection represents the recruitment of the somatodendritic AP. By comparing the dV/dt values between wild-type and Kcnq2-null neurons, we found that the first inflection was larger (control: $38.5 \pm 3.2 \mathrm{mV} / \mathrm{ms}$, $n=22 ; \mathrm{Kcnq} 2 \mathrm{cKO}: 64.7 \pm 7.8 \mathrm{mV} / \mathrm{ms}$, $n=16 ; p<0.01$, Student's $t$ test), whereas the amplitude of the second inflection was significantly smaller in the Kcnq2-null neurons (control: $226 \pm 6 \mathrm{mV} / \mathrm{ms}, n=$ 22; Kcnq2 cKO: $182 \pm 8 \mathrm{mV} / \mathrm{ms}, n=16$; $p<0.0001$, Student's $t$ test; Fig. $4 A$ ). The smaller second inflection amplitude suggests that sodium channels driving the somatodendritic AP inactivated more readily in the Kcnq2-null neurons. This is best illustrated in the AP phase plot, which was dominated by the somatodendritic component of the AP (Fig. $4 A$ ). In particular, Figure $4 A$ shows that the peak AP upstroke rate was significantly smaller (control: $226 \pm 6, n=22 ; \mathrm{Kcnq} 2 \mathrm{cKO}$ : $180 \pm 8, n=16 ; p<0.0001$, Student's $t$ test), whereas the AP threshold moved to higher values (control: $-51.4 \pm 1.6 \mathrm{mV}, n=$ 22; Kcnq2 cKO: $-36.7 \pm 5.0 \mathrm{mV}, n=16 ; p<0.01$, Student's $t$ test). Both of these changes are consistent with increased sodium channel inactivation in Kcnq2-null neurons (Battefeld et al., 2014).

What could cause the increased AP amplitude and larger first inflection in the AP dV/dt? One possibility includes changes in AIS morphology or localization. To investigate this, we tested whether the ablation of Kcnq2 also leads to changes in the AIS. We performed immunohistochemistry in brain slices from control and Kcnq2 cKO mice (Fig. 4B). We labeled the AIS using AnkG due to its prevalence throughout the neuronal subcompartment and its critical role in scaffolding sodium channels in the AIS (Cooper, 2011). By comparing control and Kcnq2-null neurons, we found that the AnkG length did not significantly change (Fig. 
A

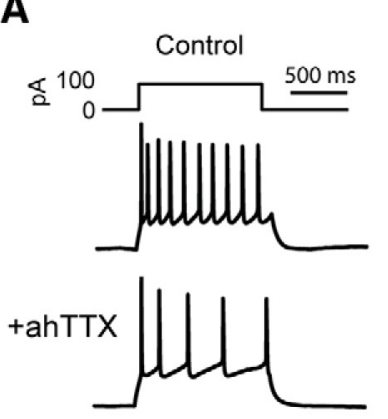

Konq2 cKO
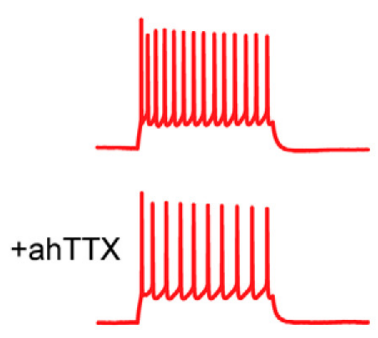

B

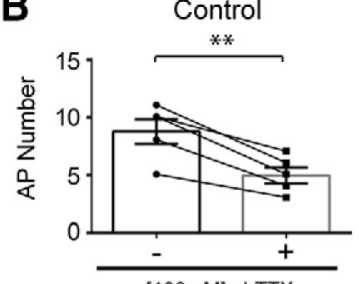

$[100 \mathrm{nM}]$ ahTTX
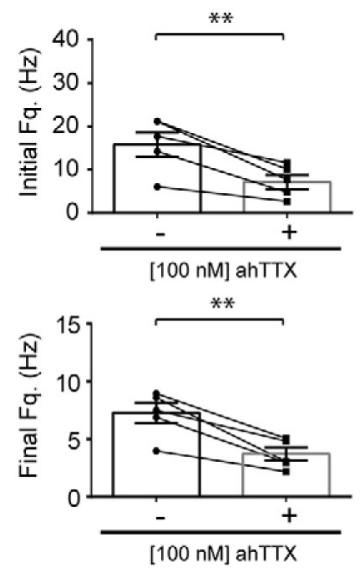

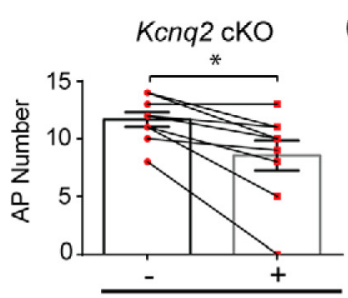

$[100 \mathrm{nM}]$ ahTTX

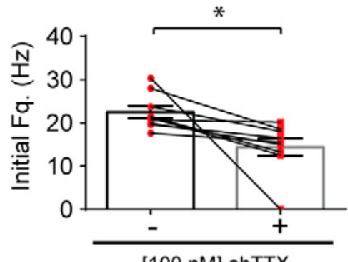

[100 nM] ahTTX

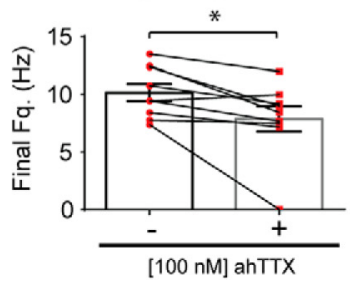

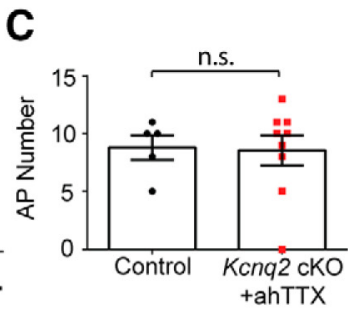
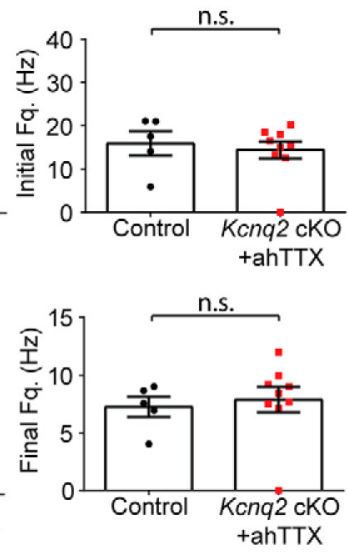

Figure 5. The $\mathrm{Na}_{\mathrm{v}} 1.6$-specific blocker 4,9-anhydroTTX dampens the hyperexcitability of $K \mathrm{cnq2}$-null neurons. $\boldsymbol{A}$, Representative voltage responses to $+100 \mathrm{pA}$ current injection steps in control (black traces) or Kcnq2-null (red traces) L2/3 pyramidal neurons in the presence or absence of $100 \mathrm{~nm}$ ahTTX. Membrane potential was kept at $-84 \mathrm{mV}$ by injecting a small DC current through the recording pipette. $\boldsymbol{B}$, Left, Summary graphs showing the effect of applying $100 \mathrm{~nm}$ ahTTX on the AP number and firing frequency of control (black) and Kcnq2-null (red) neurons (AP number: $8.8 \pm$ 1.1 to $5.0 \pm 0.7, n=5 ; p<0.01, t=6.52$; initial frequency: $15.9 \pm 2.8$ to $7.2 \pm 1.6 \mathrm{~Hz}, n=5 ; p<0.01, t=4.84$; final frequency: $7.3 \pm 0.9$ to $3.7 \pm 0.6 \mathrm{~Hz}, n=5 ; p<0.01, t=5.63$, paired Student'sttest). Right, Summary graphs showing that the application of ahTTX reduces firing properties of $K$ cnq2-null neurons (AP number: $11.7 \pm 0.6$ to $8.6 \pm 1.3, n=9 ; p<0.05, t=3.63 ;$ initial frequency: $22.5 \pm 1.4$ to $14.4 \pm 2.0 \mathrm{~Hz}, n=9 ; p<0.05, t=2.73$; final frequency: $10.2 \pm 0.7$ to $6.9 \pm 1.2 \mathrm{~Hz}, n=9 ; p<0.05, t=2.91$, paired Student's $t$ test). $C$, Summary graphs showing that the application of ahTTX reduces Kcnq2-null neurons to control levels (AP number: control ( - ahTTX), $8.8 \pm 1.1, n=5 ; K c n q 2 \mathrm{cKO}(+\mathrm{ahTTX}), 8.6 \pm 1.3, n=9 ; p=0.90 ;$ initial frequency: control ( - ahTTX), $15.9 \pm 2.8 \mathrm{~Hz}, n=5 ; \mathrm{Kcnq} 2 \mathrm{cKO}$ ( + ahTTX), $14.4 \pm 2.0 \mathrm{~Hz}, n=9 ; p=0.51$; final frequency: control $(-\operatorname{ahTTX}), 7.3 \pm 0.9 \mathrm{~Hz}, n=5 ; \mathrm{Kcnq} 2 \mathrm{cKO}(+\mathrm{ahTTX}), 6.9 \pm 1.2 \mathrm{~Hz}, n=$ $9 ; p=0.44$; Mann-Whitney test). Asterisks indicate statistically significant differences $\left({ }^{*} p<0.05,{ }^{* *} p<0.01\right)$.

4C). To measure the sodium channel distribution, we costained the AIS with a PanNa $\mathrm{v}_{\mathrm{v}}$ antibody but also found that there was no significant change in the PanNa $\mathrm{v}_{\mathrm{v}}$ length. Thus, the changes in the action potential properties may not be associated with alterations in AIS length.

\section{Inhibition of sodium channel $\mathrm{Na}_{\mathrm{v}} 1.6$ restores $\mathrm{L} 2 / 3$ excitability in Kcnq2-null neurons}

Because KCNQ2 ablation leads to action potential changes, we investigated whether targeting the sodium channel $\mathrm{Na}_{\mathrm{v}} 1.6$, which localizes at the AIS and is responsible for AP generation (Hu et al., 2009), is sufficient to dial down the hyperexcitability of Kcnq2null pyramidal neurons.

To directly test this, we took advantage of the TTX analog 4,9-ahTTX. Previous work has shown that 100 nM ahTTX blocks $50 \%$ of $\mathrm{Na}_{\mathrm{v}} 1.6$ when expressed in heterologous cells, with little to no effect on Nav1.2-another key sodium channel expressed at the AIS (Rosker et al., 2007; Hargus et al., 2013). Indeed, we found that the application of $100 \mathrm{~nm}$ ahTTX to control neurons significantly reduced the number of APs by almost $50 \%$ across a range of stimuli (control: $8.8 \pm 1.1$ to $5.0 \pm 0.7, n=5 ; p<0.01$, paired Student's $t$ test; Fig. 5). In Kcnq2-null neurons, $100 \mathrm{nM}$ ahTTX decreased the AP number less robustly, but, importantly, to levels similar to those of control neurons (Kcnq2 cKO: $11.7 \pm$ 0.6 to $8.6 \pm 1.3, n=8 ; p<0.05$, paired Student's $t$ test, Fig. $5 B$ ). A similar decrease to control levels was found for the initial and final frequencies (Fig. 5B).

$\mathrm{Na}_{\mathrm{v}} 1.6$ also contributes to the AP rheobase and resistance (input resistance-ramp; $\mathrm{R}_{\mathrm{N}}$-ramp) as neurons approach the AP threshold. This is most evident when using a slow ramp protocol, leading to the activation of a persistent sodium current, typically active between -70 and $-20 \mathrm{mV}$, which further drives the firing of pyramidal neurons (Royeck et al., 2008). Indeed, we found that in control neurons $100 \mathrm{nM}$ ahTTX increased the rheobase $(194.3 \pm 5.2$ to $236.5 \pm 19 \mathrm{pA}, n=6 ; p<0.05$, paired Student's $t$ test; Fig. 6) and decreased the approach slope to AP threshold, measured as $\mathrm{R}_{\mathrm{N}}$-ramp (236.0 \pm 15 to $200.3 \pm 13 \mathrm{M} \Omega ; n=6 ; p<$ 0.001 , paired Student's $t$ test; Fig. $6 B$ ), as expected for inhibiting an inward sodium current. Surprisingly, ahTTX had minimal effects on both the rheobase and $\mathrm{R}_{\mathrm{IN}}$-ramp when using the slow ramp protocol in Kcnq2-null neurons, despite reducing the AP number $(14.0 \pm 0.7$ to $11.0 \pm 0.6 ; n=8 ; p<0.01$, paired Student's $t$ test, Fig. $6 B$ ). This suggests that the loss of KCNQ2 channels was also accompanied by a change in the contribution of $\mathrm{Na}_{\mathrm{v}} 1.6$ channels to AP generation.

An inherent assumption to our interpretation is that ahTTX is indeed a selective blocker of $\mathrm{Na}_{\mathrm{v}} 1.6$ channels in pyramidal neurons. We tested this directly by comparing the effects of ahTTX in control and $\mathrm{Na}_{\mathrm{v}}$ 1.6-deficient neurons (Royeck et al., 2008). For this experiment, we depolarized control and $\mathrm{Na}_{\mathrm{v}} 1.6$-deficient neurons to elicit seven APs followed by bath application of 100 nM ahTTX. In control neurons, the application of ahTTX for 8-10 min was sufficient to block L2/3 pyramidal neuron firing. In contrast, ahTTX application to $\mathrm{Na}_{\mathrm{v}} 1$.6-deficient neurons had little effect (Fig. 7). This provides strong evidence that ahTTX is indeed a selective blocker at the $100 \mathrm{nM}$ concentration in neocortical pyramidal neurons. We repeated this experiment in Kcnq2null neurons and found that the application of $100 \mathrm{~nm}$ ahTTX 
A
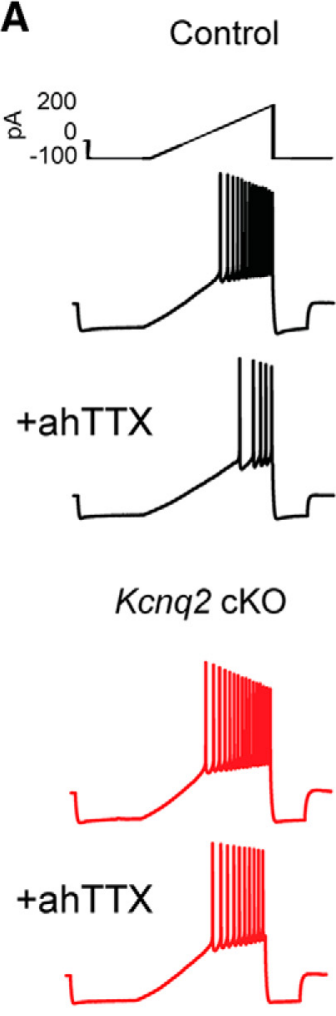

B

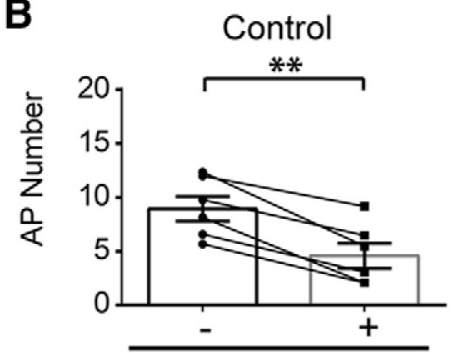

$[100 \mathrm{nM}]$ ahTTX

*

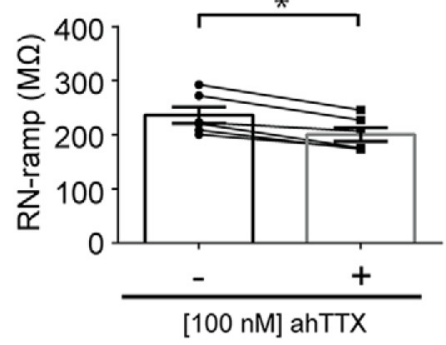

$* * *$

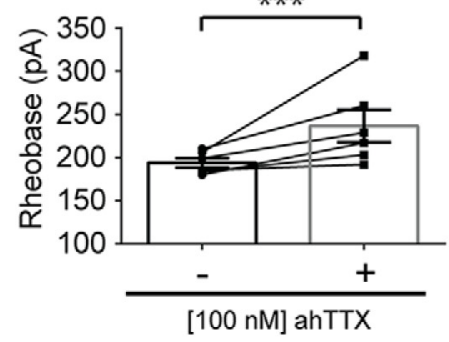

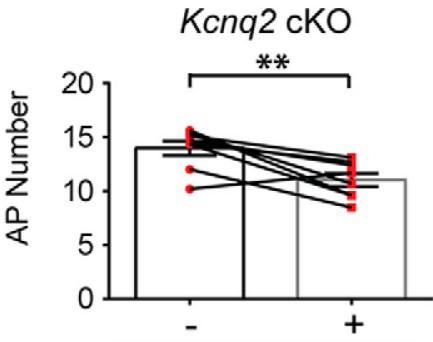

$[100 \mathrm{nM}]$ ahTTX n.s.
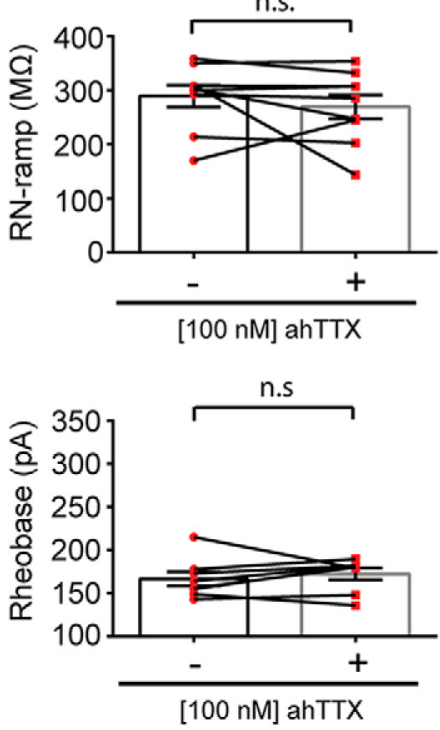

Figure 6. Kcnq2 ablation leads to a reduced role for $\mathrm{Na}_{\mathrm{v}} 1.6$ in regulating the intrinsic excitability of $\mathrm{L} 2 / 3$ pyramidal neuron. $A$, Representative voltage responses to a current injection ramp (2.5 s ramp from -100 to $+200 \mathrm{pA} ; 0.1 \mathrm{nA} / \mathrm{s}$ ) recorded from control (black traces) or Kcnq2-null (red traces) L2/3 pyramidal neurons in the presence or absence of $100 \mathrm{~nm} 4,9$-ahTTX, a Na 1.6 blocker. $B$, Left, Summary graphs showing the effect of $100 \mathrm{~nm}$ ahTTX on the number of APs, input resistance, and rheobase in control neurons (AP number: $9.0 \pm 1.1$ to $4.7 \pm 1.2, n=6 ; p<0.01, t=6.38$; rheobase: $194 \pm 5$ to $237 \pm 19 \mathrm{pA}, n=6 ; p<0.05, t=2.81 ; \mathrm{R}_{\mathrm{N}}$-ramp resistance: $236 \pm 15$ to $200 \pm 13 \mathrm{M} \Omega, n=6 ; p<0.001, t=6.97$, paired Student's test). Right, Summary graphs showing the effect of $100 \mathrm{~nm}$ ahTTX on Kcnq2-null neurons when applying a slow ramp current injection (AP number: $14.0 \pm 0.7$ to $11.0 \pm 0.6, n=8 ; p<0.01, t=3.55$; rheobase: $167 \pm 8$ to $172 \pm 7$ $\mathrm{pA}, n=8 ; p=0.468, t=0.768 ; \mathrm{R}_{\mathrm{N}}$-ramp: $324 \pm 22$ to $298 \pm 12 \mathrm{M} \Omega, n=8 ; p=0.0803, t=2.04$, paired Student's $\mathrm{t}$ test). Asterisks indicate statistically significant differences $\left({ }^{*} p<0.05{ }^{*}{ }^{*} p<\right.$ $0.01,{ }^{* * *} p<0.001$ ).

reduced the AP number by approximately the same amount as in control cells (control: $6.8 \pm 0.1$ to $4.4 \pm 0.5, n=11 ; p<0.001$; Kcnq2 cKO: $7.2 \pm 0.1$ to $4.0 \pm 1.0, n=6 ; p<0.05$, paired Student's $t$ test; Fig. 7), which is consistent with $\mathrm{Na}_{\mathrm{v}} 1.6$ maintaining persistent firing in Kcnq2-null neurons. To determine whether the firing frequency changed, we measured the interspike interval for cells before and after the addition of ahTTX. Indeed, interspike intervals at both the onset and end of the measured train showed decreased firing frequency (first interval: control, $10.9 \pm 1.0 \mathrm{~Hz}$ to $7.6 \pm 1.0 \mathrm{~Hz}, n=10 ; p<0.001 ; \mathrm{Kcnq} 2 \mathrm{cKO}$, $10.6 \pm 0.7 \mathrm{~Hz}$ to $6.0 \pm 1.2 \mathrm{~Hz}, n=5 ; p<0.05$; fourth interval: control, $6.8 \pm 0.2 \mathrm{~Hz}$ to $5.2 \pm 0.3 \mathrm{~Hz}, n=10 ; p<0.001, t=7.38$; Kcnq2 cKO, $6.7 \pm 0.2 \mathrm{~Hz}$ to $4.9 \pm 0.5 \mathrm{~Hz}, n=5 ; p<0.05$, paired Student's $t$ test; Fig. 7). These data suggest that $\mathrm{Na}_{\mathrm{v}} 1.6$ is still expressed in Kcnq2-null neurons and is critical for persistent firing, although not for setting the rheobase.

\section{Discussion}

KCNQ2 controls excitability in L2/3 somatosensory pyramidal neurons

In this study, we used cortical Kcnq2 cKO mice to show for the first time that the excitability of L2/3 pyramidal neurons critically depends on KCNQ2 channel activity. In particular, we found that Kcnq2 ablation led to an increased number of APs and to faster initial and final firing frequencies, independent of the stimulus protocol (step vs ramp). The elevated excitability was partly due to changes in the input resistance of Kcnq2-null neurons. KCNQ2 channels typically begin activating close to the resting membrane potential, and their probability of opening increases as neurons approach the AP threshold. As such, loss of this slow potassium channel conductance would lead to an elevated input resistance.

Our work also extends earlier findings; for instance, a previous study showed that the KCNQ channel blocker XE991 increased the excitability of L2/3 pyramidal neurons, accompanied by an increase in input resistance (Guan et al., 2011). However, this study used low concentrations of XE991 $(2 \mu \mathrm{M})$ that blocked only a small portion of total KCNQ channel conductance, as higher, more commonly used XE991 concentrations blocked the A-type potassium current in L2/3 pyramidal neurons (Guan et al., 2011). Other studies showed that the ablation of Kcnq2 using transgenic mice or a reduction of KCNQ2/3 activity using mice carrying BFNS variants also increased the excitability of CA1 pyramidal neurons (Otto et al., 2006; Singh et al., 2008; Soh et al., 2014; Kalappa et al., 2015). However, CA1 pyramidal neurons exhibit strong spike frequency adaptation, and the ablation of KCNQ2 channels prevented this adaptation, allowing neurons to fire continuously in a regular pattern (Peters et al., 2005; Soh et al., 2014); 
in contrast, L2/3 pyramidal neurons in our study showed much less adaptation, and the loss of KCNQ2 activity did not alter L2/3 spike frequency adaptation, as demonstrated by almost equal increases in both the initial and final firing frequencies. This suggests that channels other than KCNQ2 primarily mediate L2/3 adaptation.

\section{The KCNQ2 ${ }^{\mathrm{I205V}}$ variant increases neuronal activity similar to KCNQ2 deletion}

Within the last 4 years, $>50$ mutations relating to KCNQ2 encephalopathy have been identified (Millichap et al., 2016). Several of these variants right shift the voltage activation of KCNQ2 channels to more depolarized membrane potentials. However, such variants would leave the mAHP intact, making it difficult to predict their effect on neuronal excitability and firing. We found that the overexpression of the KCNQ2 ${ }^{\mathrm{I} 205 \mathrm{~V}}$ pathogenic variant (Weckhuysen et al., 2012) in wild-type mice, and in a subset of $\mathrm{L} 2 / 3$ pyramidal neurons, exhibited very similar neurophysiological phenotypes to Kcnq2-null neurons. In particular, KCNQ2 ${ }^{\mathrm{I} 205 \mathrm{~V}}$ expressing neurons produced more APs with faster initial and final firing frequencies than neurons overexpressing KCNQ2 wild-type channels (Fig. 3B).

One explanation for how the KCNQ2 ${ }^{\mathrm{I} 205 \mathrm{~V}}$ variant increases excitability stems from its altered channel properties. The KCNQ2 ${ }^{\mathrm{I} 205 \mathrm{~V}}$ variant shifts the voltage-activation curve of KCNQ2/3 channels to more depolarized membrane potentials, preventing any significant activation of $\mathrm{KCNQ} 2 / 3$ channels at subthreshold membrane potentials_-similar to neurons lacking $\mathrm{KCNQ} 2$ channels. As the KCNQ2 ${ }^{\mathrm{I} 205 \mathrm{~V}}$ variant is introduced in progenitor cells, it is likely that the vast majority of $\mathrm{KCNQ} 2 / 3$ channels are $\mathrm{KCNQ} 22^{\mathrm{I} 205 \mathrm{~V}} / \mathrm{KCNQ} 3$ by $\mathrm{P} 15-\mathrm{P} 20 . \mathrm{KCNQ} 2{ }^{\mathrm{I} 205 \mathrm{~V}}$ is a dominant negative, so the incorporation of even one copy of KCNQ2 ${ }^{1205 \mathrm{~V}}$ would be sufficient to change the biophysical properties of a KCNQ2/3 channel. Alternatively, the expression of the KCNQ2 ${ }^{\mathrm{I} 205 \mathrm{~V}}$ variant could lead to a trafficking defect followed by decreased surface expression of KCNQ2/3 channels. However, this seems unlikely, as the $\mathrm{mAHP}$ measured in neurons expressing the wild-type $\mathrm{KCNQ} 2$ or the KCNQ2 ${ }^{\mathrm{I} 205 \mathrm{~V}}$ variant was similar (Fig. 3D). In our protocol, the mAHP reflects the opening of KCNQ2/3 channels following a $50 \mathrm{~ms}$ suprathreshold stimulus, depolarizing neurons well beyond the activation range of both KCNQ2 and KCNQ2 ${ }^{1205 \mathrm{~V}}$ channels. Overall, our data suggest that the loss of KCNQ2 activity at subthreshold membrane potentials leads to large excitability changes that are independent of changes to the mAHP.

\section{KCNQ2 ablation alters action potential properties}

Chronic changes in neuronal excitability could lead to both electrophysiological and morphological changes in neurons. Recent work has shown that neuronal activity can also have a profound effect on the AIS - a neuronal subcompartment that is critical for the generation of APs (Grubb and Burrone, 2010; Kaphzan et al., 2011; Kole and Stuart, 2012; Hamada and Kole, 2015). In partic- ular, elevated neuronal activity could shift the AIS toward the soma and/or shorten its length. This compensatory response will decrease neuronal excitability by shifting the AP initiation site closer to the soma, thereby requiring a greater depolarization to overcome the somatic capacitive load. However, costaining for both the AIS marker AnkG and $\mathrm{Na}_{\mathrm{v}}$ channels did not reveal any changes in AIS length in Kcnq2-null neurons, suggesting that their hyperexcitability is not necessarily accompanied by alterations in AIS localization.

But why does the action potential amplitude increase in Kcnq2-null pyramidal neurons? We speculate that this might be a side effect of neuronal compensation for the loss of KCNQ2 channels in the AIS. Previous studies using pharmacological approaches and modeling have shown that a lack of KCNQ2 channels would depolarize the AIS membrane potential (Battefeld et al., 2014), leading to greater sodium channel inactivation and a subsequently smaller AP amplitude. One mechanism to counteract this effect would be to increase action potential amplitude, which is driven by changes in sodium channel density and/or voltage-gated sodium channel composition in the AIS. Such changes might explain our seemingly contradictory finding of a larger AP amplitude, yet decreased maximum upstroke rate. Future studies are needed to determine whether Kcnq2 ablation alters the sodium channel composition in the AIS.

\section{$\mathrm{Na}_{\mathrm{v}} 1.6$ is a viable target to dampen KCNQ2-related hyperexcitability}

Current treatments for children with KCNQ2 encephalopathy are limited. However, two possible interventions have been proposed: (1) retigabine (or ezogabine); and (2) carbamazepine. Re- 
tigabine is a specific Food and Drug Administration (FDA)approved KCNQ activator (Blackburn-Munro et al., 2005; Boscia et al., 2006; Gunthorpe et al., 2012) that works by stabilizing the active conformation of KCNQ channels and improving their ability to dampen neuronal excitability (Wuttke et al., 2005). As one copy of wild-type KCNQ2 channels is still present in children with KCNQ2 encephalopathy, the application of retigabine can still open KCNQ2/3 channels. However, it is currently unknown whether all KCNQ variants will respond similarly to retigabine. Additionally, several adverse effects have further limited the use of retigabine in patients (Jankovic and Ilickovic, 2013). Recently, carbamazepine, an FDA-approved compound that reduces sodium channel activity, was proposed as a first-in-line compound to treat patients with KCNQ2 encephalopathy (Pisano et al., 2015; Auvin et al., 2016). However, it is unclear which specific sodium channels are responsible for the effects produced by carbamazepine, and not all patients with KCNQ2 encephalopathy respond to carbamazepine (Weckhuysen et al., 2012; Pisano et al., 2015).

Here, we propose $\mathrm{Na}_{\mathrm{v}} 1.6$ as a new molecular target to dampen KCNQ2-mediated neuronal excitability. $\mathrm{Na}_{\mathrm{v}} 1.6$ colocalizes with KCNQ2/3 channels (Battefeld et al., 2014); thus, the loss of $\mathrm{KCNQ} 2 / 3$ channels may lead to unchecked $\mathrm{Na}_{\mathrm{v}} 1.6$ activity. This is particularly important as $\mathrm{Na}_{\mathrm{v}} 1.6$ also partially mediates the afterdepolarization following APs in some pyramidal neurons, as well as the persistent sodium current in cortical neurons (Golomb et al., 2006; Royeck et al., 2008). Importantly, KCNQ2/3 channels are known to limit the activity of these conductances (Yue and Yaari, 2004; Golomb et al., 2006). We found that the reduction of $\mathrm{Na}_{\mathrm{v}} 1.6$ activity using the TTX metabolite ahTTX led to a decrease in the number and frequency of APs, independent of the stimulation protocol (Figs. 5 , 6). Interestingly, reducing $\mathrm{Na}_{\mathrm{v}} 1.6$ activity with $100 \mathrm{nM}$ ahTTX in Kcnq2-null neurons decreased excitability to near-control levels. The addition of ahTTX on control neurons also increased the rheobase and decreased resistance $\left(\mathrm{R}_{\mathrm{N}}\right.$-ramp) when measured with the ramp protocol, which is consistent with previous work using $\mathrm{Na}_{\mathrm{v}} 1.6$ knock-out mice to show that $\mathrm{Na}_{\mathrm{v}} 1.6$ partly mediates the persistent sodium current (Royeck et al., 2008). However, we did not see any changes in rheobase or $\mathrm{R}_{\mathrm{N}}$-ramp when we applied ahTTX in Kcnq2null neurons (Fig. 6B). We foresee two possible explanations for this finding. First, a different set of sodium channels are now critical for setting the rheobase of APs in L2/3 neurons. One major candidate would be $\mathrm{Na}_{\mathrm{v}} 1.2$, which is also found in the AIS of pyramidal neurons and contributes to AP generation. Second, ablating KCNQ2 channels leads to a large $\mathrm{Na}_{\mathrm{v}} 1.6$-mediated conductance, such that ahTTX at $100 \mathrm{~nm}$ is insufficient to counteract its activity. This seems less likely, as the application of ahTTX was sufficient to reduce the persistent L2/3 firing in both wild-type and Kcnq2-null neurons (Fig. 7). Overall, the ability to reduce continuous AP firing to nearnormal levels in Kcnq2-null neurons suggests that $\mathrm{Na}_{\mathrm{v}} 1.6$ may indeed be a successful target for reducing KCNQ2-related neuronal hyperexcitability.

\section{References}

Allen K, Monyer H (2013) De novo mutations in epileptic encephalopathies. Nature 504:228-229. CrossRef Medline

Auvin S, Cilio MR, Vezzani A (2016) Current understanding and neurobiology of epileptic encephalopathies. Neurobiol Dis 92:72-89. CrossRef Medline

Battefeld A, Tran BT, Gavrilis J, Cooper EC, Kole MH (2014) Heteromeric $\mathrm{K}_{\mathrm{v}}$ 7.2/7.3 channels differentially regulate action potential initiation and conduction in neocortical myelinated axons. J Neurosci 34:3719-3732. CrossRef Medline
Bean BP (2007) The action potential in mammalian central neurons. Nat Rev Neurosci 8:451-465. CrossRef Medline

Blackburn-Munro G, Dalby-Brown W, Mirza NR, Mikkelsen JD, BlackburnMunro RE (2005) Retigabine: chemical synthesis to clinical application. CNS Drug Rev 11:1-20. CrossRef Medline

Boscia F, Annunziato L, Taglialatela M (2006) Retigabine and flupirtine exert neuroprotective actions in organotypic hippocampal cultures. Neuropharmacology 51:283-294. CrossRef Medline

Charlier C, Singh NA, Ryan SG, Lewis TB, Reus BE, Leach RJ, Leppert M (1998) A pore mutation in a novel KQT-like potassium channel gene in an idiopathic epilepsy family. Nat Genet 18:53-55. CrossRef Medline

Chen F, Becker AJ, LoTurco JJ (2014a) Contribution of tumor heterogeneity in a new animal model of CNS tumors. Mol Cancer Res 12:742-753. CrossRef Medline

Chen F, Maher BJ, LoTurco JJ (2014b) piggyBac transposon-mediated cellular transgenesis in mammalian forebrain by in utero electroporation. Cold Spring Harb Protoc 2014:741-749. CrossRef Medline

Cooper EC (2011) Made for "anchorin": Kv7.2/7.3 (KCNQ2/KCNQ3) channels and the modulation of neuronal excitability in vertebrate axons. Semin Cell Dev Biol 22:185-192. CrossRef Medline

Corteen NL, Cole TM, Sarna A, Sieghart W, Swinny JD (2011) Localization of GABA-A receptor alpha subunits on neurochemically distinct cell types in the rat locus coeruleus. Eur J Neurosci 34:250-262. CrossRef Medline

Golomb D, Yue C, Yaari Y (2006) Contribution of persistent Na+ current and M-type K+ current to somatic bursting in CA1 pyramidal cells: combined experimental and modeling study. J Neurophysiol 96:1912-1926. CrossRef Medline

Gorski JA, Talley T, Qiu M, Puelles L, Rubenstein JL, Jones KR (2002) Cortical excitatory neurons and glia, but not GABAergic neurons, are produced in the Emx1-expressing lineage. J Neurosci 22:6309-6314. Medline

Grubb MS, Burrone J (2010) Activity-dependent relocation of the axon initial segment fine-tunes neuronal excitability. Nature 465:1070-1074. CrossRef Medline

Guan D, Higgs MH, Horton LR, Spain WJ, Foehring RC (2011) Contributions of Kv7-mediated potassium current to sub- and suprathreshold responses of rat layer II/III neocortical pyramidal neurons. J Neurophysiol 106:1722-1733. CrossRef Medline

Gunthorpe MJ, Large CH, Sankar R (2012) The mechanism of action of retigabine (ezogabine), a first-in-class $\mathrm{K}+$ channel opener for the treatment of epilepsy. Epilepsia 53:412-424. CrossRef Medline

Hamada MS, Kole MH (2015) Myelin loss and axonal ion channel adaptations associated with gray matter neuronal hyperexcitability. J Neurosci 35:7272-7286. CrossRef Medline

Hargus NJ, Nigam A, Bertram EH 3rd, Patel MK (2013) Evidence for a role of Nav1.6 in facilitating increases in neuronal hyperexcitability during epileptogenesis. J Neurophysiol 110:1144-1157. CrossRef Medline

Hu W, Tian C, Li T, Yang M, Hou H, Shu Y (2009) Distinct contributions of $\mathrm{Na}(\mathrm{v}) 1.6$ and $\mathrm{Na}(\mathrm{v}) 1.2$ in action potential initiation and backpropagation. Nat Neurosci 12:996-1002. CrossRef Medline

Jankovic S, Ilickovic I (2013) The preclinical discovery and development of ezogabine for the treatment of epilepsy. Expert Opin Drug Discov 8:14291437. CrossRef Medline

Kalappa BI, Soh H, Duignan KM, Furuya T, Edwards S, Tzingounis AV, Tzounopoulos T (2015) Potent KCNQ2/3-specific channel activator suppresses in vivo epileptic activity and prevents the development of tinnitus. J Neurosci 35:8829-8842. CrossRef Medline

Kaphzan H, Buffington SA, Jung JI, Rasband MN, Klann E (2011) Alterations in intrinsic membrane properties and the axon initial segment in a mouse model of Angelman syndrome. J Neurosci 31:17637-17648. CrossRef Medline

Kato M, Yamagata T, Kubota M, Arai H, Yamashita S, Nakagawa T, Fujii T, Sugai K, Imai K, Uster T, Chitayat D, Weiss S, Kashii H, Kusano R, Matsumoto A, Nakamura K, Oyazato Y, Maeno M, Nishiyama K, Kodera $\mathrm{H}$, et al (2013) Clinical spectrum of early onset epileptic encephalopathies caused by KCNQ2 mutation. Epilepsia 54:1282-1287. CrossRef Medline

Kole MH, Stuart GJ (2012) Signal processing in the axon initial segment. Neuron 73:235-247. CrossRef Medline

Millichap JJ, Park KL, Tsuchida T, Ben-Zeev B, Carmant L, Flamini R, Joshi N, Levisohn PM, Marsh E, Nangia S, Narayanan V, Ortiz-Gonzalez XR, Patterson MC, Pearl PL, Porter B, Ramsey K, McGinnis EL, Taglialatela M, Tracy M, Tran B, et al (2016) KCNQ2 encephalopathy: features, mu- 
tational hot spots, and ezogabine treatment of 11 patients. Neurol Genet 2:e96. CrossRef Medline

Orhan G, Bock M, Schepers D, Ilina EI, Reichel SN, Löffler H, Jezutkovic N, Weckhuysen S, Mandelstam S, Suls A, Danker T, Guenther E, Scheffer IE, De Jonghe P, Lerche H, Maljevic S (2014) Dominant-negative effects of KCNQ2 mutations are associated with epileptic encephalopathy. Ann Neurol 75:382-394. CrossRef Medline

Otto JF, Yang Y, Frankel WN, White HS, Wilcox KS (2006) A spontaneous mutation involving Kcnq2 ( $\left.\mathrm{K}_{\mathrm{v}} 7.2\right)$ reduces M-current density and spike frequency adaptation in mouse CA1 neurons. J Neurosci 26:2053-2059. CrossRef Medline

Pan Z, Kao T, Horvath Z, Lemos J, Sul JY, Cranstoun SD, Bennett V, Scherer SS, Cooper EC (2006) A common ankyrin-G-based mechanism retains KCNQ and $\mathrm{Na}_{\mathrm{v}}$ channels at electrically active domains of the axon. J Neurosci 26:2599-2613. CrossRef Medline

Peters HC, Hu H, Pongs O, Storm JF, Isbrandt D (2005) Conditional transgenic suppression of $\mathrm{M}$ channels in mouse brain reveals functions in neuronal excitability, resonance and behavior. Nat Neurosci 8:51-60. CrossRef Medline

Pisano T, Numis AL, Heavin SB, Weckhuysen S, Angriman M, Suls A, Podesta B, Thibert RL, Shapiro KA, Guerrini R, Scheffer IE, Marini C, Cilio MR (2015) Early and effective treatment of KCNQ2 encephalopathy. Epilepsia 56:685-691. CrossRef Medline

Rosker C, Lohberger B, Hofer D, Steinecker B, Quasthoff S, Schreibmayer W (2007) The TTX metabolite 4,9-anhydro-TTX is a highly specific blocker of the $\mathrm{Na}(\mathrm{v} 1.6)$ voltage-dependent sodium channel. Am J Physiol Cell Physiol 293:C783-C789. CrossRef Medline

Royeck M, Horstmann MT, Remy S, Reitze M, Yaari Y, Beck H (2008) Role of axonal NaV1.6 sodium channels in action potential initiation of CA1 pyramidal neurons. J Neurophysiol 100:2361-2380. CrossRef Medline

Saitsu H, Kato M, Koide A, Goto T, Fujita T, Nishiyama K, Tsurusaki Y, Doi H, Miyake N, Hayasaka K, Matsumoto N (2012) Whole exome sequenc- ing identifies KCNQ2 mutations in Ohtahara syndrome. Ann Neurol 72:298-300. CrossRef Medline

Siddiqi F, Chen F, Aron AW, Fiondella CG, Patel K, LoTurco JJ (2014) Fate mapping by piggyBac transposase reveals that neocortical GLAST + progenitors generate more astrocytes than Nestin + progenitors in rat neocortex. Cereb Cortex 24:508-520. CrossRef Medline

Singh NA, Charlier C, Stauffer D, DuPont BR, Leach RJ, Melis R, Ronen GM, Bjerre I, Quattlebaum T, Murphy JV, McHarg ML, Gagnon D, Rosales TO, Peiffer A, Anderson VE, Leppert M (1998) A novel potassium channel gene, KCNQ2, is mutated in an inherited epilepsy of newborns. Nat Genet 18:25-29. CrossRef Medline

Singh NA, Otto JF, Dahle EJ, Pappas C, Leslie JD, Vilaythong A, Noebels JL, White HS, Wilcox KS, Leppert MF (2008) Mouse models of human KCNQ2 and KCNQ3 mutations for benign familial neonatal convulsions show seizures and neuronal plasticity without synaptic reorganization. J Physiol 586:3405-3423. CrossRef Medline

Soh H, Pant R, LoTurco JJ, Tzingounis AV (2014) Conditional deletions of epilepsy-associated KCNQ2 and KCNQ3 channels from cerebral cortex cause differential effects on neuronal excitability. J Neurosci 34:53115321. CrossRef Medline

Weckhuysen S, Mandelstam S, Suls A, Audenaert D, Deconinck T, Claes LR, Deprez L, Smets K, Hristova D, Yordanova I, Jordanova A, Ceulemans B, Jansen A, Hasaerts D, Roelens F, Lagae L, Yendle S, Stanley T, Heron SE, Mulley JC, et al (2012) KCNQ2 encephalopathy: emerging phenotype of a neonatal epileptic encephalopathy. Ann Neurol 71:15-25. CrossRef Medline

Wuttke TV, Seebohm G, Bail S, Maljevic S, Lerche H (2005) The new anticonvulsant retigabine favors voltage-dependent opening of the Kv7.2 (KCNQ2) channel by binding to its activation gate. Mol Pharmacol 67: 1009-1017. CrossRef Medline

Yue C, Yaari Y (2004) KCNQ/M channels control spike afterdepolarization and burst generation in hippocampal neurons. J Neurosci 24:4614-4624. CrossRef Medline 